\title{
Front Matter: Volume 8813
}

, "Front Matter: Volume 8813," Proc. SPIE 8813, Spintronics VI, 881301 (26 September 2013); doi: 10.1117/12.2033957

SPIE Event: SPIE NanoScience + Engineering, 2013, San Diego, California, United SPIE. States 


\title{
PROCEEDINGS OF SPIE
}

\section{Spintronics VI}

\author{
Henri-Jean Drouhin \\ Jean-Eric Wegrowe \\ Manijeh Razeghi \\ Editors
}

\section{5-29 August 2013}

San Diego, California, United States

Sponsored and Published by

SPIE 
The papers included in this volume were part of the technical conference cited on the cover and title page. Papers were selected and subject to review by the editors and conference program committee. Some conference presentations may not be available for publication. The papers published in these proceedings reflect the work and thoughts of the authors and are published herein as submitted. The publisher is not responsible for the validity of the information or for any outcomes resulting from reliance thereon.

Please use the following format to cite material from this book:

Author(s), "Title of Paper," in Spintronics VI, edited by Henri-Jean Drouhin, Jean-Eric Wegrowe, Manijeh Razeghi, Proceedings of SPIE Vol. 8813 (SPIE, Bellingham, WA, 2013) Article CID Number.

ISSN: 0277-786X

ISBN: 9780819496638

Published by

SPIE

P.O. Box 10, Bellingham, Washington 98227-0010 USA

Telephone +1 3606763290 (Pacific Time) · Fax +1 3606471445

SPIE.org

Copyright @ 2013 , Society of Photo-Optical Instrumentation Engineers.

Copying of material in this book for internal or personal use, or for the internal or personal use of specific clients, beyond the fair use provisions granted by the U.S. Copyright Law is authorized by SPIE subject to payment of copying fees. The Transactional Reporting Service base fee for this volume is $\$ 18.00$ per article (or portion thereof), which should be paid directly to the Copyright Clearance Center (CCC), 222 Rosewood Drive, Danvers, MA 01923. Payment may also be made electronically through CCC Online at copyright.com. Other copying for republication, resale, advertising or promotion, or any form of systematic or multiple reproduction of any material in this book is prohibited except with permission in writing from the publisher. The CCC fee code is $0277-786 \mathrm{X} / 13 / \$ 18.00$.

Printed in the United States of America.

Publication of record for individual papers is online in the SPIE Digital Library.

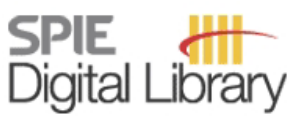

SPIEDigitalLibrary.org

Paper Numbering: Proceedings of SPIE follow an e-First publication model, with papers published first online and then in print and on CD-ROM. Papers are published as they are submitted and meet publication criteria. A unique, consistent, permanent citation identifier (CID) number is assigned to each article at the time of the first publication. Utilization of CIDs allows articles to be fully citable as soon as they are published online, and connects the same identifier to all online, print, and electronic versions of the publication. SPIE uses a six-digit CID article numbering system in which:

- The first four digits correspond to the SPIE volume number.

- The last two digits indicate publication order within the volume using a Base 36 numbering

system employing both numerals and letters. These two-number sets start with 00, 01, 02, 03, 04,

05, 06, 07, 08, 09, 0A, OB ... 0Z, followed by 10-1Z, 20-2Z, etc.

The CID Number appears on each page of the manuscript. The complete citation is used on the first page, and an abbreviated version on subsequent pages. Numbers in the index correspond to the last two digits of the six-digit CID Number. 


\title{
Contents
}

\author{
ix Conference Committee \\ xiii Introduction
}

\section{SKYRMIONS}

881307 Ultrafast generation of nanostructures with tunable topological properties by single laser pulse illumination (Invited Paper) [8813-6]

M. Finazzi, Politecnico di Milano (Italy); M. Savoini, Politecnico di Milano (Italy) and Radboud Univ. Nijmegen (Netherlands); A. R. Khorsand, Radboud Univ. Nijmegen (Netherlands); A. Tsukamoto, A. Itoh, Nihon Univ. (Japan); L. Duò, Politecnico di Milano (Italy); A. Kirilyuk, T. Rasing, Radboud Univ. Nijmegen (Netherlands); M. Ezawa, The Univ. of Tokyo (Japan)

\section{SPIN SEEBECK EFFECTS AND HEAT TRANSPORT II}

$88130 \mathrm{~A}$ Thermal creation of a spin current by Seebeck spin tunneling (Invited Paper) [8813-9] R. Jansen, National Institute of Advanced Industrial Science and Technology (Japan); J. C. Le Breton, Foundation for Fundamental Research on Matter (Netherlands); A. M. Deac, Helmholtz-Zentrum Dresden-Rossendorf e. V. (Germany); H. Saito, S. Yuasa, National Institute of Advanced Industrial Science and Technology (Japan)

$88130 \mathrm{C}$ Thermokinetic considerations about spin-dependent voltage generated by heat currents (Invited Paper) [8813-11]

J.-E. Wegrowe, H.-J. Drouhin, Ecole Polytechnique, CNRS (France) and CEA/DSM/IRAMIS (France)

\section{QUANTUM DOTS}

8813 OF Single spins in semiconductor quantum dot microcavities (Invited Paper) [8813-14] S. Höfling, Julius-Maximilians-Univ. Würzburg (Germany) and Stanford Univ. (United States); K. De Greve, P. L. McMahon, D. Press, L. Yu, J. S. Pelc, C. M. Natarajan, N. Y. Kim, T. Ladd, Stanford Univ. (United States); E. Abe, Stanford Univ. (United States) and National Institute of Informatics (Japan); S. Maier, D. Bisping, F. Langer, C. Schneider, M. Kamp, JuliusMaximilians-Univ. Würzburg (Germany); R. H. Hadfield, Heriot-Watt Univ. (United Kingdom); A. Forchel, M. M. Fejer, Julius-Maximilians-Univ. Würzburg (Germany); Y. Yamamoto, Stanford Univ. (United States) and National Institute of Informatics (Japan)

$8813 \mathrm{OH}$ Magnetism of magnetic ion doped semiconductor nanocrystals (Invited Paper) [8813-16] S.-J. Zou, S.-J. Cheng, National Chiao Tung Univ. (Taiwan) 
$8813 \mathrm{OL}$ Magnetospectroscopy of HgTe based topological insulators (Invited Paper) [8813-20] F. Teppe, TeraHertz Lab., CNRS, Univ. Montpellier 2 (France); M. Zholudev, TeraHertz Lab., CNRS, Univ. Montpellier 2 (France) and Institute for Physics of Microstructures (Russian Federation); M. Orlita, Lab. National des Champs Magnetiques Intenses, CNRS (France); C. Consejo, N. Diakonova, D. But, D. Coquillat, W. Knap, TeraHertz Lab., CNRS, Univ. Montpellier 2 (France); N. N. Mikhailov, S. A. Dvoretskii, A.V. Rzhanov Institute of Semiconductor Physics (Russian Federation); V. Aleshkin, V. Gavrilenko, Institute for Physics of Microstructures (Russian Federation)

\section{NEW MATERIALS}

881300 A new twist on organic spintronics: controlling transport in organic sandwich devices using fringe fields from ferromagnetic films (Invited Paper) [8813-23]

M. Wohlgenannt, M. E. Flatté, N. J. Harmon, F. Wang, The Univ. of lowa (United States);

A. D. Kent, F. Macià, New York Univ. (United States); P. Fischer, M.-Y. Im, Lawrence Berkeley National Lab. (United States)

$8813 \mathrm{OR}$ Nonlocal, local, and extraction spin valves based on ferromagnet/semiconductor hybrid structures consisting of the Heusler alloy $\mathrm{Co}_{2} \mathrm{FeSi}$ on GaAs (Invited Paper) [8813-26] M. Ramsteiner, Y. Manzke, P. Bruski, R. Farshchi, J. Herfort, Paul-Drude-Institut für Festkörperelektronik (Germany)

\section{SPIN OPTICS I}

8813 OY Expanded horizons for generating and exploring optical angular momentum in vortex structures (Keynote Paper) [8813-33]

D. L. Andrews, M. M. Coles, M. D. Williams, D. S. Bradshaw, Univ. of East Anglia (United Kingdom)

$88130 Z$ Spin-orbit interactions in vortex singularimetry (Invited Paper) [8813-34]

J. B. Götte, Max-Planck-Institut für Physik komplexer Systeme (Germany); M. R. Dennis, Univ. of Bristol (United Kingdom)

881310 Quantum information processing with spin-orbit laser modes (Invited Paper) [8813-35] A. Z. Khoury, C. E. R. Souza, A. R. Vieira, Univ. Federal Fluminense (Brazil); M. O. Hor-Meyll, Univ. Federal do Rio de Janeiro (Brazil)

\section{SPIN OPTICS II}

881314 Spinoptical metamaterials: spin-controlled photonics based on symmetry violation (Invited Paper) [8813-39]

N. Shitrit, I. Yulevich, E. Maguid, D. Ozeri, D. Veksler, V. Kleiner, E. Hasman, Technion-Israel Institute of Technology (Israel) 
881318 Spin injection, transport, and relaxation in spin light-emitting diodes: magnetic field effects (Invited Paper) [8813-43]

H. Höpfner, C. Fritsche, A. Ludwig, A. Ludwig, Ruhr-Univ. Bochum (Germany); F. Stromberg,

H. Wende, W. Keune, Univ. Duisburg-Essen (Germany); D. Reuter, Univ. Paderborn

(Germany); A. D. Wieck, N. C. Gerhardt, M. R. Hofmann, Ruhr-Univ. Bochum (Germany)

\section{SPIN INJECTION II}

$88131 \mathrm{C}$ Photoinduced inverse spin-Hall effect in Pt/GaAs and Pt/Ge (Invited Paper) [8813-47]

F. Bottegoni, A. Ferrari, G. Isella, S. Cecchi, M. Finazzi, F. Ciccacci, Politecnico di Milano (Italy)

SPIN TRANSFER

$88131 \mathrm{~K}$ Ferromagnetic resonance detection by a point-contact bolometer (Invited Paper) [8813-55]

H. Seinige, C. Wang, M. Tsoi, The Univ. of Texas at Austin (United States)

\section{OXIDE AND MULTIFERROICS I}

$88131 \mathrm{~L} \quad$ Electric-field control of magnetism in an insulator at room temperature: the case of multiferroic $\mathrm{BiFeO}_{3}$ (Invited Paper) [8813-56]

R. de Sousa, Univ. of Victoria (Canada)

\section{OXIDE AND MULTIFERROICS II}

8813 IR Effect of fast strain on Co/Pt multilayers with perpendicular anisotropy (Invited Paper) [8813-62]

U. Singh, S. Adenwalla, Univ. of Nebraska-Lincoln (United States)

\section{SPIN DYNAMICS}

$88131 \mathrm{Y}$ A theory of quantum dynamics of a nanomagnet under excitation (Keynote Paper) [8813-68]

L. J. Sham, Univ. of California, San Diego (United States)

\section{GRAPHENE I}

881328 A systematic approach to interpreting Hanle spin precession data in non-local spin valves (Invited Paper) [8813-78]

A. G. Swartz, K. M. McCreary, W. Han, H. Wen, R. K. Kawakami, Univ. of California, Riverside (United States) 
8813 2A Ultrafast spin-polarized vertical-cavity surface-emitting lasers (Invited Paper) [8813-80] N. C. Gerhardt, H. Höpfner, M. Lindemann, M. Li, H. Jähme, Ruhr-Univ. Bochum (Germany); T. Ackemann, Univ. of Strathclyde (United Kingdom); M. R. Hofmann, Ruhr-Univ. Bochum (Germany)

$88132 \mathrm{C}$ Semiconductor optical isolators for integrated optics (Invited Paper) [8813-82] H. Shimizu, Tokyo Univ. of Agriculture and Technology (Japan)

$88132 \mathrm{E} \quad$ High-performance spintronic computing with magnetoresistive semiconductor heterojunctions (Invited Paper) [8813-105]

J. S. Friedman, B. W. Wessels, A. V. Sahakian, Northwestern Univ. (United States)

\section{GRAPHENE II AND RELATED MATERIALS}

$88132 \mathrm{H} \quad$ Spin-valley coupling in atomically thin dichalcogenides (Invited Paper) [8813-86]

$X$. Cui, The Univ. of Hong Kong (Hong Kong, China)

881321 Optical manipulation and electrical control of valley pseudo-spins in atomically thin semiconductors (Invited Paper) [8813-87]

S. Wu, J. S. Ross, C. Huang, Univ. of Washington (United States); N. J. Ghimire, The Univ. of Tennessee (United States) and Oak Ridge National Lab. (United States); J. Yan, Oak Ridge National Lab. (United States) and The Univ. of Tennessee (United States); D. G. Mandrus, The Univ. of Tennessee (United States) and Oak Ridge National Lab. (United States); D. Xiao, Carnegie Mellon Univ. (United States); W. Yao, The Univ. of Hong Kong (Hong Kong, China); D. H. Cobden, X. XU, Univ. of Washington (United States)

\section{DEVICES II}

$88132 \mathrm{~J}$ Magnetic field controlled reconfigurable logic gates with integrated nanomagnets (Invited Paper) [8813-88] M. Johnson, U.S. Naval Research Lab. (United States); J. Song, Korea Institute of Science and Technology (Korea, Republic of); J. Hong, Korea Univ. (Korea, Republic of); J. Chang, Korea Institute of Science and Technology (Korea, Republic of)

$88132 \mathrm{~K}$ Soft $\mathrm{x}$-ray microscopy: facing the mesoscale challenge in magnetism (Invited Paper) [8813-89]

P. Fischer, M.-Y. Im, Lawrence Berkeley National Lab. (United States); J.-I. Hong, Daegu Gyeongbuk Institute of Science and Technology (Korea, Republic of)

$88132 \mathrm{~L} \quad$ Spin wave logic devices for general and special task data processing (Invited Paper) [8813-90]

A. Khitun, Univ. of California, Riverside (United States) 
881320 Spin pumping at Permalloy/graphene interface (Invited Paper) [8813-93]

S. Singh, Univ. of Central Florida (United States); D. Markó, National Univ. of Singapore

(Singapore); E. del Barco, Univ. of Central Florida (United States); B. Özyilmaz, National Univ. of Singapore (Singapore)

\section{DEVICES III}

$88132 Q \quad$ Structural optimization of MTJs with a composite free layer (Invited Paper) [8813-95]

A. Makarov, V. Sverdlov, S. Selberherr, Technische Univ. Wien (Austria)

881325 Introducing and manipulating magnetic dopant exchange interactions in semiconductor nanowires (Invited Paper) [8813-97]

M. Hegde, I. D. Hosein, T. Sabergharesou, S. S. Farvid, P. V. Radovanovic, Univ. of Waterloo (Canada)

\section{SPIN-ORBIT INTERACTION AND SPIN RELAXATION}

$88132 \mathrm{~V}$ Measurement of spin-flip scattering and photon echo response in GaMnAs (Invited Paper) [8813-100]

K. C. Hall, D. Webber, M. Yildirim, S. A. March, R. Mathew, A. Gamouras, Dalhousie Univ. (Canada); M. Dobrowolska, X. Liu, J. K. Furdyna, Univ. of Notre Dame (United States)

$88132 \mathrm{~W}$ Intrinsic normal Zeeman effect for spin plasmons in semiconductor quantum wells (Invited Paper) [8813-101]

C. A. Ullich, Univ. of Missouri-Columbia (United States); I. D'Amico, The Univ. of York (United Kingdom); F. Baboux, F. Perez, Institut des Nanosciences de Paris, CNRS, Univ. Paris VI (France)

$88132 X$ Spins in silicon MOSFETs: electron spin relaxation and hyperpolarization of nuclear spins (Invited Paper) [8813-102]

C. C. Lo, Univ. College London (United Kingdom); C. D. Weis, Lawrence Berkeley National Lab. (United States); J. van Tol, National High Magnetic Field Lab. (United States); J. Bokor, Univ. of California, Berkeley (United States); T. Schenkel, Lawrence Berkeley National Lab. (United States); J. J. L. Morton, Univ. College London (United Kingdom)

$88132 Y$ Discontinuous envelope function in semiconductor heterostructures (Invited Paper) [8813-103]

H.-J. Drouhin, Ecole Polytechnique, CNRS (France) and CEA-IRAMIS (France); F. Bottegoni, Ecole Polytechnique, CNRS (France), CEA-IRAMIS (France), and Politecnico di Milano (Italy); T. L. H. Nguyen, Institute of Physics (Viet Nam); J.-E. Wegrowe, Ecole Polytechnique, CNRS (France) and CEA-IRAMIS (France); G. Fishman, Institut d'Électronique Fondamentale, CNRS (France)

Author Index 


\title{
Conference Committee
}

\author{
Symposium Chairs
}

Satoshi Kawata, Osaka University (Japan)

Manijeh Razeghi, Northwestern University (United States)

\section{Symposium Cochairs}

David L. Andrews, University of East Anglia Norwich (United Kingdom) James G. Grote, Air Force Research Laboratory (United States)

\section{Conference Chairs}

Henri-Jean Drouhin, Ecole Polytechnique (France) Jean-Eric Wegrowe, Ecole Polytechnique (France) Manijeh Razeghi, Northwestern University (United States)

\section{Conference Program Committee}

Jack Bass, Michigan State University (United States)

Franco Ciccacci, Politecnico di Milano (Italy)

Russell P. Cowburn, University of Cambridge (United Kingdom)

Vincent Cros, Unité Mixte de Physique CNRS/Thales (France)

Hanan Dery, University of Rochester (United States)

Michel I. Dyakonov, Université Montpellier 2 (France)

Michael E. Flatté, The University of lowa (United States)

Jean-Marie George, Unité Mixte de Physique CNRS/Thales (France)

Erez Hasman, Technion-Israel Institute of Technology (Israel)

Henri Jaffrès, Unité Mixte de Physique CNRS/Thales (France)

Andrew D. Kent, New York University (United States)

Giti A. Khodaparast, Virginia Polytechnic Institute and State University (United States)

Mathias Klaui, Universität Konstanz (Germany)

Ryan McClintock, Northwestern University (United States)

Laurens W. Molenkamp, Julius-Maximilians-Universität Würzburg

(Germany)

Hiro Munekata, Tokyo Institute of Technology (Japan)

Yoshichika Otani, The University of Tokyo (Japan)

Dafiné Ravelosona, Institut d'Électronique Fondamentale (France)

Nitin Samarth, The Pennsylvania State University (United States)

Alain Schuhl, Institut NÉEL (France)

Jing Shi, University of California, Riverside (United States)

Donald J. Silversmith, Defense Threat Reduction Agency (United States)

Luc Thomas, Headway Technology (United States)

Evgeny Tsymbal, University of Nebraska-Lincoln (United States) 
Olaf M. J. van 't Erve, U.S. Naval Research Laboratory (United States) Joerg Wunderlich, Hitachi Cambridge Laboratory (United Kingdom) Igor Zutic, University at Buffalo (United States)

\section{Session Chairs}

1 Spin Seebeck Effects and Heat Transport I

Chia-Ling Chien, Johns Hopkins University (United States)

2 Skyrmions

Markus Donath, Westfälische Wilhelms-Universität Münster (Germany)

3 Spin Seebeck Effects and Heat Transport II

Sadamichi Maekawa, Japan Atomic Energy Agency (Japan)

4 Quantum Dots

Henri Jaffrès, Unité Mixte de Physique CNRS/Thales (France)

5 Spin Seebeck Effects and Heat Transport III

Burkard Hillebrands, Technische Universität Kaiserslautern (Germany)

6 Topological Insulators

Inanc Adagideli, Sabanci University (Turkey)

7 New Materials

Charles Gould, Julius-Maximilians-Universität Würzburg (Germany)

8 Topological Insulators and States

Julie Karel, Max-Planck-Institut für Chemische Physik Fester Stoffe (Germany)

9 Spin Optics I

Natalia M. Litchinitser, University at Buffalo (United States)

10 Spin Optics II

Antonio Z. Khoury, Universidade Federal Fluminense (Brazil)

11 Spin Injection I

Masashi Shiraishi, Osaka University (Japan)

12 Spin Injection II

Ron Jansen, National Institute of Advanced Industrial Science and Technology (Japan)

13 Cold Atoms

Joerg B. Goette, Max-Planck-Institut für Physik komplexer Systeme (Germany) 
14 Spin Transfer

Igor Zutic, University at Buffalo (United States)

15 Oxide and Multiferroics I

Chris Leighton, University of Minnesota (United States)

16 Oxide and Multiferroics II

Shireen Adenwalla, University of Nebraska-Lincoln (United States)

17 Spin Hall Effect

Jean-Eric Wegrowe, Ecole Polytechnique (France)

18 Spin Dynamics

Scott A. Crooker, Los Alamos National Laboratory (United States)

19 Spin-Orbit Interaction

Henri-Jean Drouhin, Ecole Polytechnique (France)

20 Graphene I

Roland Winkler, Northern Illinois University (United States)

Abdelmadjid Anane, Université Paris-Sud, CNRS (France)

21 Devices |

Margaret Dobrowolska, University of Notre Dame (United States)

22 Graphene II and Related Materials

Saroj Dash, Chalmers University of Technology (Sweden)

23 Devices II

Siegfried Selberherr, Technische Universität Wien (Austria)

24 Graphene III

Gernot Guntherodt, RWTH Aachen (Germany)

25 Devices III

Jaroslav Fabian, Universität Regensburg (Germany)

26 Spin-Orbit Interaction and Spin Relaxation

Irene D'Amico, The University of York (United Kingdom) 


\section{Introduction}

The sixth edition of the Spintronics symposium of the SPIE conference gathered more than one hundred speakers in San Diego from Sunday 25 to Thursday 29 August 2013.

As for the five previous editions, the symposium covered the main topics of Spintronics, witnessing for the dynamism of a very active field of research. These proceedings report some important results presented at the meeting and the aim of the present introduction is to give an echo of the informal and fruitful discussions. Many open questions have been debated, including some recurrent puzzling problems discussed since the beginning of the Spintronics conferences.

The symposium was divided into 26 sessions that covered: Spin-Seebeck effects (two sessions), skyrmions, quantum dots, topological insulators (two sessions), new materials, spin optics (two sessions), spin injection (2 sessions), cold atoms, spin transfer, oxides and multiferroics (two sessions), spin Hall effect, spin dynamics, spin orbit (two sessions), graphene (three sessions), and devices (three sessions).

This 6th edition of the symposium confirms the interest for the hot topics, e.g. Spin Caloritronics (present in the sessions devoted to spin Seebeck effects and spin Hall effects), spin-optics (see the keynote presentation of D. L. Andrews in this proceedings), topological insulators, skyrmions, domain wall motion (see the keynote of S. S. P. Parkin), and graphene. The frontier topic of spin physics based on cold atoms has been introduced in the present Spintronics VI edition (with the keynote lecture of M. Di Ventra). L. J. Sham introduced the session 18 of spin dynamics with "A theory of quantum dynamics of a nanomagnet under excitations" (see these proceedings).

The traditional topics of spintronics are however still very present (spin injection, spin dynamics, spin transfer, spin Hanle effect, spin Hall effects, spin pumping), with some new experimental observations together with persistent interrogations about the very nature of spin currents. Some of the problems had been put forward at the first Spintronics symposia (see e.g. the keynote of M. I. Dyakonov in 2008 and later that of E. Sonin in 2011), and are still under debate. Indeed, the difficulty of defining univocally the spin current is present for both the fundamental quantum current in the presence of spin-orbit interactions, and also for the macroscopic pure spin currents that flow without electric current but in the presence of spin dependent scattering. This puzzling situation about some basic physical properties impacts the descriptions of recent experimental results, based on, for example, spin Seebeck effects, spin Hanle and inverse spin Hanle effects, spin Hall and inverse spin Hall effects, thermal or non-local spin transfer, etc. 
Overall, the conference was an invaluable opportunity for open exchange and stimulating discussions in a friendly atmosphere.

We are grateful to SPIE, to the Program Committee, and to all speakers and authors that have made this conference a success.

Henri-Jean Drouhin

Jean-Eric Wegrowe

Manijeh Razeghi 